FLARING ARCH STRUCTURE OF LARGE ERUPTIVE PIIENOMENA AND RIGID ROTATION

Z. Mouradian, I. Soru-Escaut

Observatoire de Paris-Meudon. U.A. $320^{\circ}$

F-92195 Meudon Principal Cedex

ABSTRACT - Considering the flaring arch to be the basic element of all flares, we study here the structure of compact flares and double ribbon flares. It is observed that, in the case of compact flares, the flaring arch diverges from a pivot point (rigid rotation), while in the case of double ribbon flares the flaring arches are distributed to either side of the polarity reversal line.

Solar flares can be subdivided into two categories according to their morphological structure: compact flares and double ribbon fläres. Moreover, we have shown (Mouradian et al., 1983) that the flaring arch is the basic element of all flares.

\title{
FLARING ARCH
}

The flaring arch is a magnetic structure existing prior to the flare, and which suddenly becomes emissive in $H a$. EUV and $X$. A flaring arch develops to either side of a magnetic field reversal line. The arch is asymmetrical, with one of its feet - the min one - being the point from which the flare propagates. An wumple of a flaring arch observed in X-rays by Skylab is given in Eddy (1979).

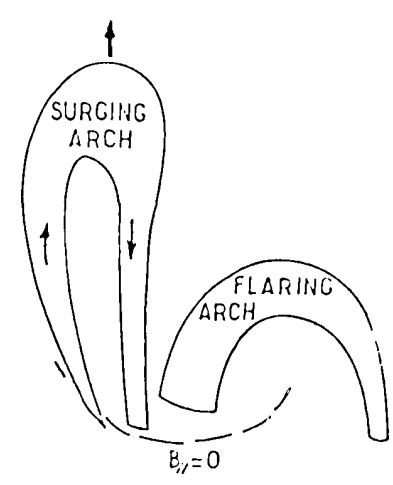

Figure 1 
larother flare elentent ls the surging arch. which is a

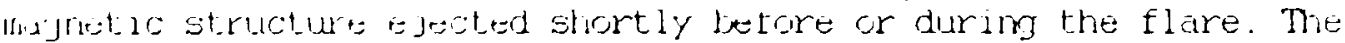
almplest form of a flare is a structure with a sirgle flarirg

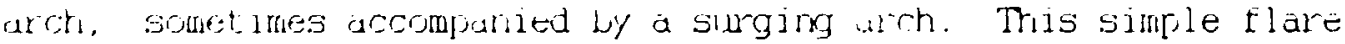
is called ar "elenterlary enptive roterolueron" (FPP) and is diagrarnifed ja frgure 1 (Flare of 1980, sept. 6, at 13:00 (TT).

CMLAC:! l'LALI:Y;

Compuct: tlares are formed by flaring arches that diverge from a lisvete loullit.

Iri nosit custe. flares conprise a certain number of 1. laring alches (abl), all of which have their main foot in a

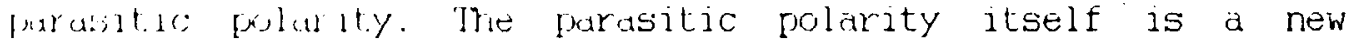

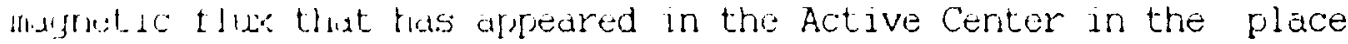
(s) a rejura of l rald rotution called a "pivot point". Starting in 1983- pinet ponts lave been detected ard related with the

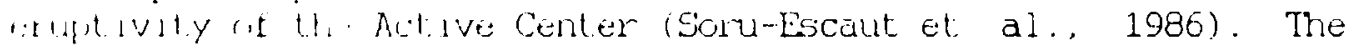

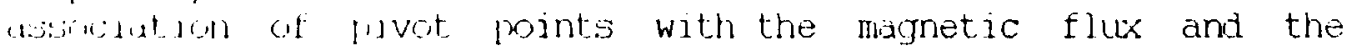
luasital polarities wus made in Martres et al. (1986) ard Mildilian at al. (1947). In tigure 3, we give the scheme of a mill 1, le arch lare (15630, Oct.19. at 09:00 UT) that starts from

Figure 2

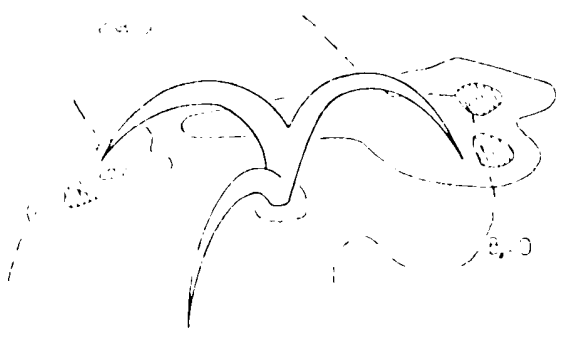

the purasitic polarity (pivot point) as the HXIS observations (comlesy of $G$. Simnte) reveal it to us (Mouradian et al., 1988, Sinnet et al, 1980). Thls flare is the second of a series of three wurlikg in the srace of one hour. Thic three flares satisfy the knwlogy olubon lefined by Martres et al., (1984), i.e. several successive flares in the same area having at least one struelure in cormon. This homology criterion is explained by the tad that the main toot of the flures is always the same (the parusitic morlly) while the place where the al hes loop back (secorkidry ficet) may change. The puvot point is therefore the wint of depmture for the flare and remains fixed both during a blen 1 late and from one flare to the next. 


\section{COUBLE RIBEON FLALWS}

On September 4, 1982, the PA 18549 (KALE) / USAG Region $38853830^{\circ}$ produced a compact flare at about 00:30 UT and a clouble riblem. flare at about 02:00 UT, visible on the Meinon spectroheliogram at Do:52 UT (figure 3).

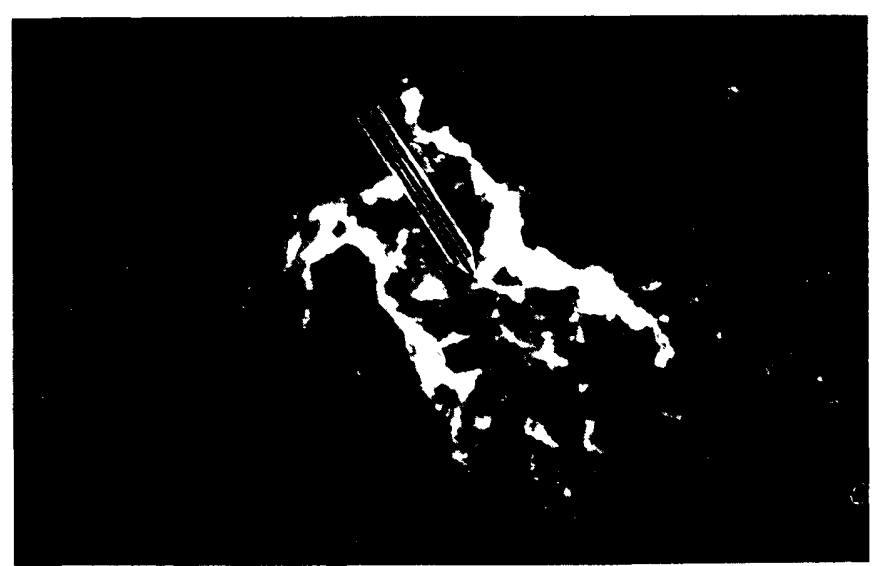

Figura 3

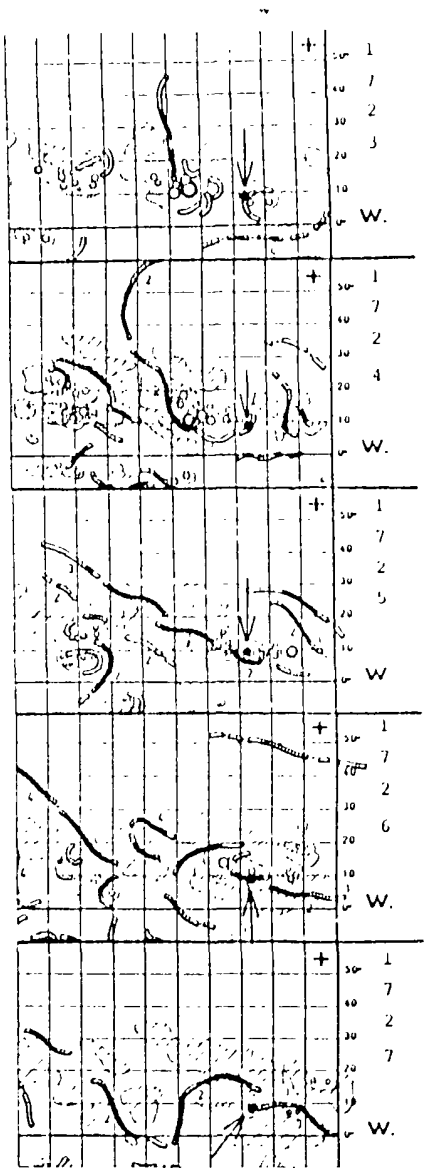

Figure 4
The evolution of these flares is given by Moristrita (1907). The pivot point for the two flares formed during rotations 1723 to 1726 and persistad into rotation 1727 (figure 4). Ihis figure, estiblished with the Meudon Synoptic Charts, follows a given longitude through different rotations. It can be seen that successive filaments cross each other at the same heliographic coordinates as those of the pivot point (arrows), during five rotations. Its presence irdicates the existence of a rigid rotation. The point is also the point of departure of the two flares. During the double ribton flare, the two structures diverge from the two sides of the filamerit but the ribbon to the north remains "attached" to the pivot poirt (arrow in figure 3).

Another double ribbon flare is thie one of June 6. 1982, at $16: 29$, with which we can study

the flaring arch system. We see in figure 5 that the points of 
dipulture (figure $5 a$ ), which are the mann feet, are located on the two sidiss of the prolarity reversal line. and touch each other on the orposite silirs as they evolve (figure '5b). The polarity revirsal line is located at the same point as a filament present
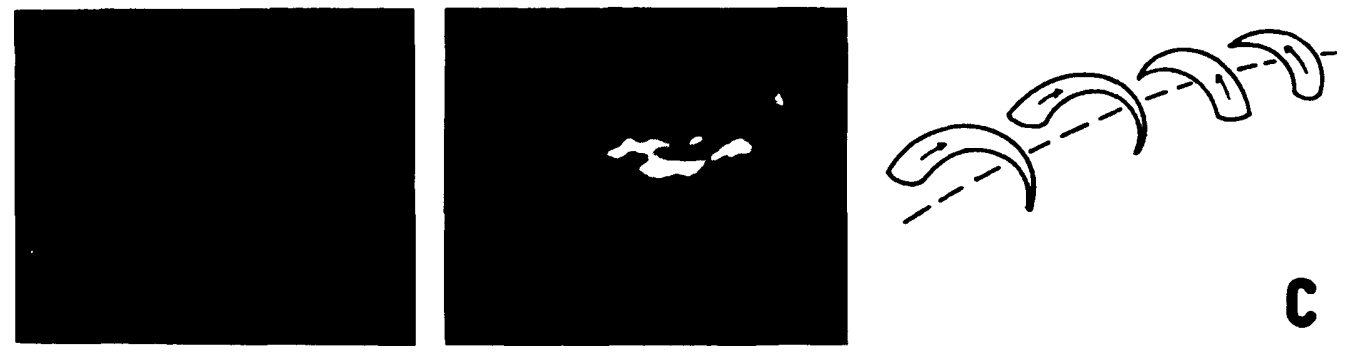

Figure 5

t.wo rotations before (Soru-Escaut et al., 1985), which shows the uxistence of a rigid rotation. In figure 5c, we give the scheme of the flaring arch system.

All of the examples given here have in cominon the fact that the pivot point remains fixed during the flare and becomes one with its point of departure.

The flure scenarios described above are valid only for those cases where ther" $j: 3$ no magnetic reconnection. In the presence of reconifucluons, the flaring arch identity is destroyed.

\section{REFERENCES}

Exdy, J.A. 1979 : A New Sun, the Solar Results From Skylab, NASA, ST - 402, p. 148 .

Murtres. M.J., Woadgate. B.E., Mein. N., Mouradian, Z., Rayrole. J., Schmieder. B. . Simon, G., Soru-Escaut, I. : 1984, F.B.S., Homologous Flares group - Part I. Adv. Space Res., Vol. 14. P. 5 .

Martres. M.J.. Mouradian, 2., Soru-Escaut, I., : 1986, Astron. Astrophys. 161, 376.

Mrishita. 11. : 1907. Selected Solar lkr Photographs, Tokyo Astronomical Obzervatory. Mitaka, p. 32.

Mourutian, ?.. Martres. M.J., Sonl-Escaut, I. : 1983, Solar Phys. 87. 309 .

Mouradian, 2. Martres, M.J., Soru-Escaut, I., Gesztelyi, L. : 1987. Astron. Astrophys. 183, 129.

Muluadian. 2.. Martres, M.J., Soru-Escaut, I., Simnett, G.M. : 1983. Astron. Astrophys. (submitted).

Sinnetl. G.M. . Mouradian, Z., Martres, M.J., Soru-Escaut, I. : 1988. Astron. Astrophys. (submitted).

Sorul Boraut. [.. Murtres, M.J., Mouradian, Z. : 1985, Ristron. Autrophys. 145. 19.

Suru-Ficaut. I. Martres. M.J., Mouradian, 2. : 1986, S.T.P. Procecting of Workshop at Meudon, France, June 18-22, 1984.

P.A. Simon, G. Hectman. M.A. Shea, (eds.) p. 186. 